Article

\title{
One-Pot Synthesis and Characterization of Novel Shape-Memory Poly( $\varepsilon$-Caprolactone) Based Polyurethane-Epoxy Co-networks with Diels-Alder Couplings
}

\author{
Katalin Czifrák ${ }^{1}$, Csilla Lakatos ${ }^{1}$, József Karger-Kocsis ${ }^{2,3, *}$ (D) , Lajos Daróczi ${ }^{4}$, Miklós Zsuga ${ }^{1}$ \\ and Sándor Kéki 1,* (iD) \\ 1 Department of Applied Chemistry, University of Debrecen, Egyetem tér 1, H-4032 Debrecen, Hungary; \\ czifrak.katalin@science.unideb.hu (K.C.); lakatoscsilla@science.unideb.hu (C.L.); \\ zsuga.miklos@science.unideb.hu (M.Z.) \\ 2 Department of Polymer Engineering, Faculty of Mechanical Engineering, Budapest University of \\ Technology and Economics, Múegyetem rkp. 3, H-1111 Budapest, Hungary \\ 3 MTA-BME Research Group for Composite Science and Technology, Múegyetem rkp. 3, H-1111 Budapest, \\ Hungary \\ 4 Department of Solid State Physics, University of Debrecen, Bem tér 18/b, H-4026 Debrecen, Hungary; \\ lajos.daroczi@science.unideb.hu \\ * Correspondence: karger@pt.bme.hu (J.K.-K.); keki.sandor@science.unideb.hu (S.K.); Tel.: +36-1-463-2497 \\ (J.K.-K.); +36-52-512-900 (ext. 22455) (S.K.)
}

Received: 7 April 2018; Accepted: 3 May 2018; Published: 6 May 2018

\begin{abstract}
The present work aimed at the preparation and investigation of different epoxypolyurethane (EP-PU) co-networks. The EP-PU co-networks were obtained by applying two different synthetic strategies, in which the coupling element, the Diels-Alder (DA) adduct, was prepared previously or formed "in situ" in the reaction between furan functionalized polyurethane and furfuryl amine-diglycidyl ether bisphenol-A oligomers (FA_DGEBA). For the synthesis of these EP-PU networks, poly( $\varepsilon$-caprolactone)-diol (PCD, $M_{\mathrm{n}}=2 \mathrm{~kg} / \mathrm{mol}$ ) and poly( $\varepsilon$-caprolactone) (PCL) with different molecular weights $\left(M_{\mathrm{n}}=10,25\right.$ and $\left.50 \mathrm{~kg} / \mathrm{mol}\right)$ and 1,6-hexamethylenediisocyanate (HDI) were used. The EP-PU co-networks were characterized by Attenuated Total Reflectance Fourier-Transform Infrared spectroscopy (AT-FT-IR), differential scanning calorimetry (DSC) and dynamical mechanical analysis (DMA). Scanning electron microscopy (SEM) was applied to assess the morphology of the EP-PU samples. It was demonstrated that the stress-strain curves for the EP-PUs could be interpreted based on the Standard Linear Solid (SLS) model. The DMA traces of some EP-PUs (depending on the composition and the synthetic method) revealed a plateau-like region above the melting temperature $\left(T_{\mathrm{m}}\right)$ of PCL confirming the presence of cross-linked structure. This feature predicted shape memory (SM) behavior for these EP-PU samples. Indeed, very good shape fixity and moderate shape recovery were obtained. The shape recovery processes of these EP-PU samples were described using double exponential decay functions.
\end{abstract}

Keywords: epoxy resin; polyester polyurethane; Diels-Alder adduct; polycaprolactone; co-network; shape recovery; stress-strain behavior; modeling

\section{Introduction}

Epoxy resins (EPs) are well-known for their versatile applications covering coatings, adhesives and matrices of composites [1-4]. The widespread use EPs is mostly due to their good mechanical 
properties, and high thermal and chemical stabilities. However, their cross-linked networks make EPs intrinsically brittle materials. Thus, EPs exhibit low toughness and ductility which strongly limit their application fields [5]. To overcome these limitations, one of the strategies is to introduce flexible polymer chains into the network providing it with better deformability and yielding higher toughness. For the network modification polyurethanes (PUs) are often the preferred additives due their versatile chemistry [6].

There are numerous reports for the preparation EP-PU systems in which different interpenetrating network (IPN) were formed [7-12]. Furthermore, incorporations of Diels-Alder (DA) adducts into different polymeric systems have paved the way for the preparation of networks with thermally reversible couplings [13-16]. The related systems exhibit self-healing [17-19], shape memory (SM) behavior [20,21], and even a combination of self-healing and SM, denoted as Diels-Alder shape memory-assisted self-healing [22].

Stemming from previous studies, it can be expected that the relative amount of DA adducts strongly affect the abovementioned functional properties. It is intuitive that reduction of the chain segment's length between DA moieties is a straightforward approach to enhance the concentration of DA couplings. This is frequently followed in poly( $\varepsilon$-caprolactone) (PCL)-containing polymers [19,20], covering also PUs [21,22]. Note that, in these systems, the melting/crystallization of PCL serves for the reversible switch function of their SM behavior. There is a further, yet less explored, possibility following the same principle (i.e., segment's length reduction), namely creation of co-networks involving DA linkages. For the generation of co-networks, the combination of EP and PU chemistries seem to be a proper way. This is reasoned by the chemical reactions between them along with the fact that the most used polymers to demonstrate the possibilities of thermoreversible DA couplings are EPand PU-based ones. Thus, in this study, we focused on the synthesis and characterizations of EP-PU co-networks containing both crystalline PCL segments and DA adducts to achieve good SM properties. In this work, two synthesis methods were followed. In the first approach, the co-networks were derived via the reaction of isocyanate terminated poly(E-caprolactone) prepolymers with the hydroxyl terminated Diels-Alder adduct (synthesized by the reaction of furfuryl alcohol with 1,1'-(methylene di-4,1-phenylene)bismaleimide (BMI) and bisphenol A diglycidyl ether oligomer (DGEBA). According to the second synthetic path, DGEBA was first reacted with furfurylamine (FA), and this compound (FA_DGEBA oligomer) reacted further with furanyl terminated poly ( $\varepsilon$-caprolactone) containing PU in the presence of BMI. The DA adducts were in both cases reaction products of furan and maleimide, however, in the first case they were previously synthesized, whereas in the second pathway in situ produced. The effects of the composition and the DA-adducts on the mechanical, thermomechanical properties and morphologies of these crosslinked EP-PU hybrids were assessed and discussed.

\section{Materials and Methods}

\subsection{Materials}

For the synthesis of the EP-PU co-networks, the following chemicals were used: Poly ( $\varepsilon$-caprolactone)-diol (PCD, $M_{\mathrm{n}}=2 \mathrm{~kg} / \mathrm{mol}$ ) and poly( $\varepsilon$-caprolactone) (PCL, $M_{\mathrm{n}}=10 \mathrm{~kg} / \mathrm{mol}$ ) from Sigma-Aldrich (Darmstadt, Germany). PCLs with $M_{\mathrm{n}}=25$ and $50 \mathrm{~kg} / \mathrm{mol}$ were purchased from Perstorp Holding AB (Malmö, Sweden), 1,6-hexamethylene diisocyanate (HDI) (reagent grade), Furfurylamine (FA), Furfurylalcohol (Falc), 1,1'-(methylene di-4,1-phenylene)bismaleimide (BMI) (reagent grade), $\mathrm{N}, \mathrm{N}$-dimethylformamide (anhydrous $99.8 \%$ ) and Tin(II)ethylhexanoate (reagent grade) were obtained from Sigma-Aldrich (Darmstadt, Germany). Bisphenol A diglycidyl ether type EP oligomer (DGEBA, epoxy equivalent weight: $182-192 \mathrm{~g} / \mathrm{mol}$ ) was provided by Alvinplast (Budapest, Hungary). For crosslinking, Jeffamine EDR-176 (amine equivalent weight: $44 \mathrm{~g} / \mathrm{mol}$ ) from Hunstman Corporation (Pétfürdő, Hungary) were applied. Toluene (analytical grade) from Sigma-Aldrich (Darmstadt, Germany) was distilled over $\mathrm{P}_{2} \mathrm{O}_{5}$ and stored on sodium wire until use. 
2.2. Synthesis of DA Adduct from Furfuryl Alcohol and BMI

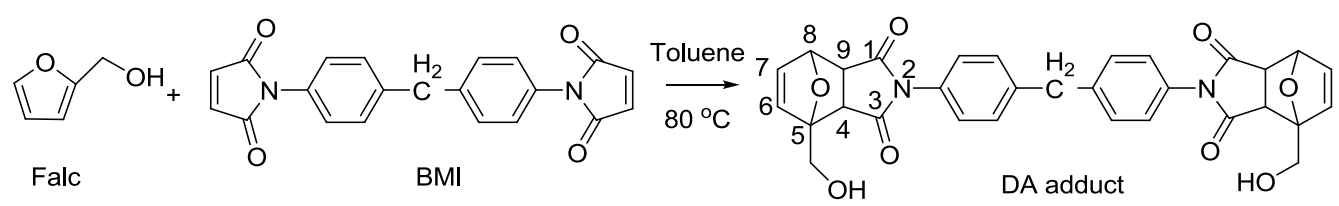

The synthesis of the DA adduct -see the above scheme- was performed similarly to those reported in Ref. [23]. Furfuryl alcohol (Falc) $(1 \mathrm{~g})\left(880 \mu \mathrm{L}, 1.02 \times 10^{-2} \mathrm{~mol}, 2\right.$ equivalent) and BMI (1.826 g, $5.095 \times 10^{-3} \mathrm{~mol}, 1$ equivalent) were dissolved in dry toluene $(10 \mathrm{~mL})$ and heated for 2 days at $75-80{ }^{\circ} \mathrm{C}$. The precipitate was filtrated and washed with diethyl ether to give $2.60 \mathrm{~g} 92 \%$ yellow crystalline product, mainly the exo isomer. ${ }^{1} \mathrm{H}$ NMR: $\left(360 \mathrm{MHz}, \mathrm{CDCl}_{3}\right) \delta$ (ppm): (exo isomer) 7.40-7.23 (8H, m, ArH), $6.74\left(2 \mathrm{H}, \mathrm{d}, J=5.6 \mathrm{~Hz}, \mathrm{H}-6, \mathrm{H}-6^{\prime}\right), 6.66\left(2 \mathrm{H}, \mathrm{d}, J=5.6 \mathrm{~Hz}, \mathrm{H}-7, \mathrm{H}-7^{\prime}\right), 5.45(2 \mathrm{H}$, d, $\left.J<1 \mathrm{~Hz}, \mathrm{H}-8, \mathrm{H}-8^{\prime}\right), 4.23(2 \mathrm{H}, \mathrm{s}, \mathrm{OH}), 4.11\left(2 \mathrm{H}, \mathrm{s}, \mathrm{ArCH} \mathrm{H}_{2} \mathrm{Ar}\right), 3.23\left(2 \mathrm{H}, \mathrm{dd}, J=6.5,<1 \mathrm{~Hz},-\mathrm{CH}_{2} \mathrm{OH}\right)$, $3.19\left(2 \mathrm{H}, \mathrm{dd}, J=6.5,<1 \mathrm{~Hz},-\mathrm{CH}_{2} \mathrm{OH}\right), 2.45-2.43\left(4 \mathrm{H}, \mathrm{m}, \mathrm{H}-9, \mathrm{H}-9^{\prime}, \mathrm{H}-4, \mathrm{H}-4^{\prime}\right)$.

\subsection{Functionalization of DGEBA Resin}

The synthesis route was similar to that one reported in Ref. [24]. FA $\left(2.45 \mathrm{~mL}, 2.8 \times 10^{-2} \mathrm{~mol}\right.$, 2 equivalent) and DGEBA ( $5 \mathrm{~g}, 1.4 \times 10^{-2} \mathrm{~mol}, 1$ equivalent $)$ were mixed in dry toluene $(25 \mathrm{~mL})$ and reacted at $100{ }^{\circ} \mathrm{C}$ for $24 \mathrm{~h}$. The obtained dark red solution was used in further reactions after ${ }^{1} \mathrm{H}$ NMR and MALDI-TOF MS (the experimental conditions detailed later) analysis (see Figures 1 and 2).
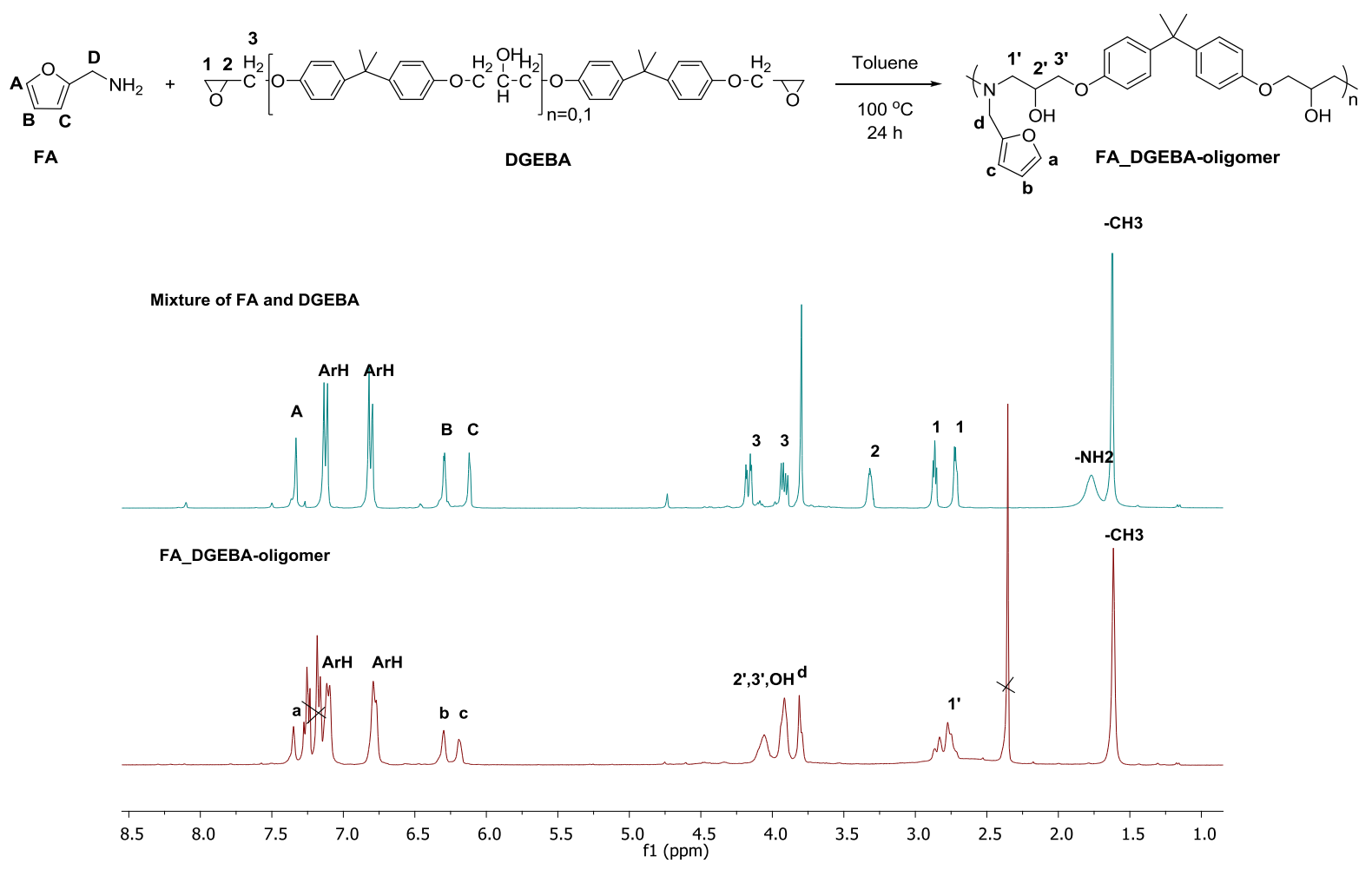

Figure 1. Cont. 


\begin{tabular}{|c|c|c|}
\hline Compound & Protons & $\sigma(\mathrm{ppm}) / \mathrm{CDCl}_{3}$ \\
\hline \multirow{5}{*}{ FA } & A & 7.32 \\
\hline & $\mathrm{B}$ & 6.30 \\
\hline & $\mathrm{C}$ & 6.11 \\
\hline & $\mathrm{D}$ & 3.79 \\
\hline & $\mathrm{NH}_{2}$ & 1.75 \\
\hline \multirow{5}{*}{ DGEBA } & $\mathrm{ArH}$ & 7.11 and 6.80 \\
\hline & $1\left(\mathrm{CH}_{2}\right.$ epoxy ring $)$ & $2.87,2.71$ \\
\hline & 2 (CH epoxy ring) & 3.32 \\
\hline & $3\left(-\mathrm{CH}_{2}-\mathrm{O}-\right)$ & $4.16,3.92$ \\
\hline & $-\mathrm{CH}_{3}$ & 1.61 \\
\hline \multirow{9}{*}{ FA_DGEBA-oligomer } & a & 7.25 \\
\hline & $\mathrm{b}$ & 6.80 \\
\hline & c & 6.19 \\
\hline & d & 3.81 \\
\hline & $1^{\prime}\left(\mathrm{CH}_{2}\right.$ from epoxy ring) & $2.85-2.75$ \\
\hline & $2^{\prime}$ (CH from epoxy ring) & 4.06 \\
\hline & $3^{\prime}\left(-\mathrm{CH}_{2}-\mathrm{O}-\right)$ & $3.81,3.92$ \\
\hline & $-\mathrm{OH}$ & 4.06 \\
\hline & $-\mathrm{CH}_{3}$ & 1.61 \\
\hline
\end{tabular}

Figure 1. ${ }^{1} \mathrm{H}$ NMR spectra of FA_DGEBA oligomer and its starting compounds as well as their assignations.

As seen in Figure 1, the signal at 3.32 ppm, corresponding to that of the epoxy protons of DGEBA, completely disappeared indicating complete reaction of the epoxy groups with the amine moiety of FA. In addition, MALDI-TOF MS measurements confirmed the presence of FA_DGEBA oligomers with different number of repeat units $(m, n)$ and FA end-groups as seen in Figure 2.

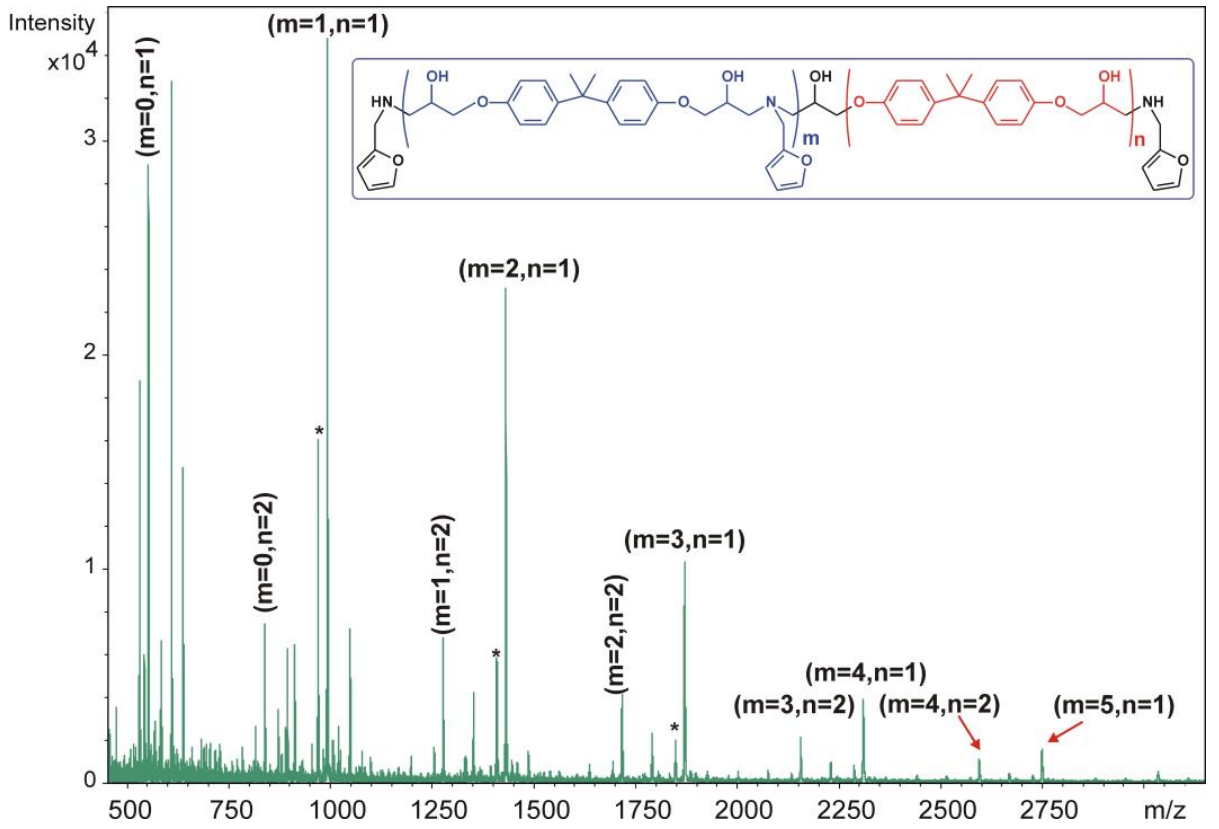

Figure 2. MALDI-TOF MS spectrum of FA_DGEBA oligomer. The numbers at the top of the peaks stand for the number of repeat units. Peaks denoted by $\left(^{*}\right)$ are the protonated oligomers $\left([\mathrm{M}+\mathrm{H}]^{+}\right)$. 
The $M_{n}$ and the number average functionality of the FA_DGEBA oligomer $\left(f_{n}\right)$ were determined by MALDI-TOF MS by using Equations (1) and (2):

$$
\begin{gathered}
M_{n}=\frac{\sum_{i=1}^{k} I_{i} M_{i}}{\sum_{i=1}^{k} I_{i}} \\
f_{n}=\frac{\sum_{i=1}^{k} I_{i} f_{i}}{\sum_{i=1}^{k} I_{i}}
\end{gathered}
$$

where $M_{\mathrm{i}}, f_{\mathrm{i}}$ and $I_{\mathrm{i}}$ are the mass (without cation), the functionality and the MALDI-TOF MS intensity of the $i$ th member of the FA_DGEBA oligomer series, respectively.

The values of $M_{\mathrm{n}}$ and $f_{\mathrm{n}}$ of the FA_DGEBA oligomer series were determined to be $1150 \mathrm{~g} / \mathrm{mol}$ and $3.3 \mathrm{~g} / \mathrm{mol}$, respectively. In these calculations (Equations (1) and (2)), it was assumed that the ionization efficiencies are independent of the mass of the oligomer species.

\subsection{Synthesis of DGEBA-PU Co-network with DA Adduct}

The DGEBA-PU co-networks contain PCLs with different molecular weights (i.e., PCD and PCL), EP and DA adduct, also in different amounts. The synthetic pathway of the preparation of EP-PU 1-15 samples is summarized in Scheme 1. Samples EP-PU 1-15 were prepared as described in the following section.

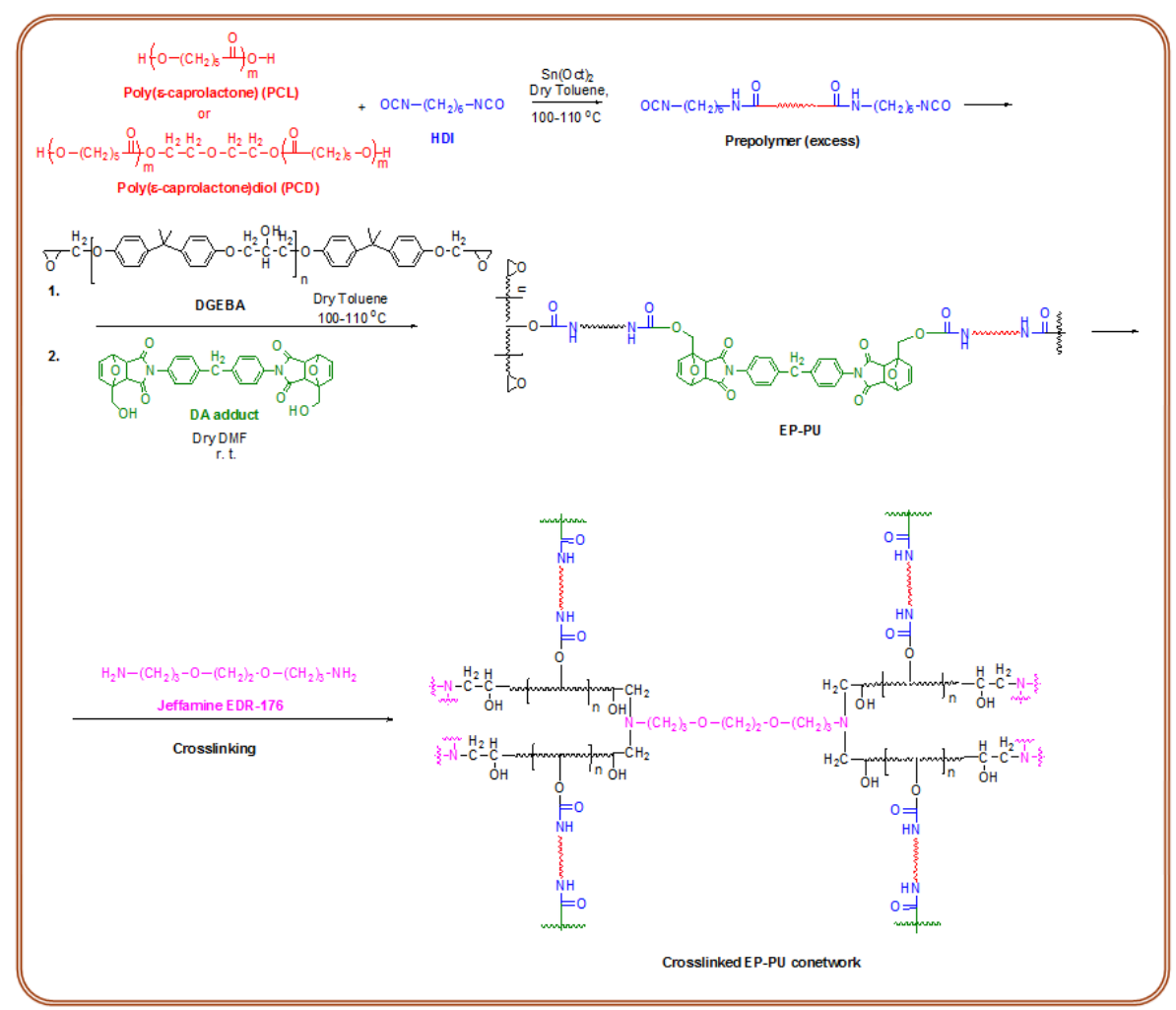

Scheme 1. Synthetic pathway for the preparation of EP-PU co-networks (EP-PUs 1-15) containing DA-adducts. 
Representative procedure for the synthesis of EP-PU 2: $0.6 \mathrm{~g} \mathrm{PCD}\left(3 \times 10^{-4} \mathrm{~mol}, \mathrm{M}_{\mathrm{n}}=2 \mathrm{~kg} / \mathrm{mol}\right)$ was dissolved in hot toluene $60-80^{\circ} \mathrm{C}(50 \mathrm{~mL})$ under a nitrogen atmosphere in a $250 \mathrm{~mL}$ four-neck flask (equipped with mechanical stirrer, dropping funnel, condenser and nitrogen inlet). Tin(II) ethylhexanoate in $2 \mathrm{~mol} \%$ amount was used as catalyst. To obtain the prepolymer with isocyanate end groups, $0.10 \mathrm{~g}(97 \mu \mathrm{L}) \mathrm{HDI}\left(6 \times 10^{-4} \mathrm{~mol}\right.$, 2 equivalent $)$ was added to the mixture and reacted for $2 \mathrm{~h}$ at $100-110^{\circ} \mathrm{C}$. Then, the epoxy resin (DGEBA) $0.11 \mathrm{~g}\left(3 \times 10^{-4} \mathrm{~mol}, 1\right.$ equivalent) was added in one portion and stirred further $1 \mathrm{~h}$ at $100-110^{\circ} \mathrm{C}$. The DA adduct $0.165 \mathrm{~g}\left(3 \times 10^{-4} \mathrm{~mol}, 1\right.$ equivalent $)$ and were dissolved in dry DMF $(1 \mathrm{~mL})$ and added to the isocyanate ended prepolymer solution in one portion at room temperature and the reaction mixture was kept at this temperature for $24 \mathrm{~h}$. The composition of this EP-PU 2 is PCD(2)-HDI-DA adduct-DGEBA/1:2:1:1, where (2) refers to the $M_{n}$ of PCD expressed in $\mathrm{kg} / \mathrm{mol}$ unit. EP-PUs 1 and 3-9 were synthesized according to the procedure described above (EP-PU networks).

To crosslink EP-Pus, Jeffamine (JA) as curing agent in 1 equivalent to DGEBA was added to the reaction mixture at $40{ }^{\circ} \mathrm{C}$ and stirred for $3 \mathrm{~h}$ vigorously (crosslinked EP-PU co-networks, designated as EP-PU 10-15). The corresponding molar ratios in the feed of the synthesized EP-PU 1-15 are summarized in Table 1.

Table 1. The corresponding molar ratios in the feed of the EP-PUs 1-15 synthesized. The number in the parenthesis represents the $M_{n}$ of the PCD or PCL expressed in $\mathrm{kg} / \mathrm{mol}$ unit.

\begin{tabular}{cc}
\hline Sample & Composition/Molar Ratios in the Feed \\
\hline EP-PU 1 & PCD(2)-HDI-DA adduct-DGEBA/1:2:0.5:0.5 \\
EP-PU 2 & PCD(2)-HDI-DA adduct-DGEBA/1:2:1:1 \\
EP-PU 3 & PCL(10)-HDI-DA adduct-DGEBA/1:2:1:1 \\
EP-PU 4 & PCL(25)-HDI-DA adduct-DGEBA/1:2:1:1 \\
EP-PU 5 & PCL(50)-HDI-DA adduct-DGEBA/1:2:1:1 \\
EP-PU 6 & PCD(2)-HDI-DA adduct-DGEBA/1:2:2:2 \\
EP-PU 7 & PCL(10)-HDI-DA adduct-DGEBA/1:2:2:2 \\
EP-PU 8 & PCL(25)-HDI-DA adduct-DGEBA/1:2:2:2 \\
EP-PU 9 & PCL(50)-HDI-DA adduct-DGEBA/1:2:2:2 \\
EP-PU 10 & PCL(10)-HDI-DA adduct-DGEBA-JA/1:2:1:1:1 \\
EP-PU 11 & PCL(25)-HDI-DA adduct-DGEBA-JA/1:2:1:1:1 \\
EP-PU 12 & PCL(50)-HDI-DA adduct-DGEBA-JA/1:2:1:1:1 \\
EP-PU 13 & PCL(10)-HDI-DA adduct-DGEBA-JA/1:2:2:2:2 \\
EP-PU 14 & PCL(25)-HDI-DA adduct-DGEBA-JA/1:2:2:2:2 \\
EP-PU 15 & PCL(50)-HDI-DA adduct-DGEBA-JA/1:2:2:2:2 \\
\hline
\end{tabular}

The mixtures were poured onto Teflon ${ }^{\circledR}$ plates and dried in air yielding the final EP-PU co-networks in form of elastic films. The final co-networks were obtained after $24 \mathrm{~h}$ curing at $60^{\circ} \mathrm{C}$.

\subsection{Synthesis of FA-DGEBA Oligomer-PU Networks}

The synthesized EP-PU co-networks differed in the $M_{n}$ of PCL and weight ratio of the FA_DGEBA oligomer applied. The synthetic approach for the preparation of EP-PU 16-24 samples is summarized in Scheme 2. EP-PU 16 sample was prepared as described below.

Representative procedure for the synthesis of EP-PU 16: $3.0 \mathrm{~g}$ PCL $\left(3 \times 10^{-4} \mathrm{~mol}, M_{\mathrm{n}}=10 \mathrm{~kg} / \mathrm{mol}\right)$ was dissolved in hot toluene $60-80{ }^{\circ} \mathrm{C}(50 \mathrm{~mL})$ under a nitrogen atmosphere in a $250 \mathrm{~mL}$ four-neck flask (equipped with mechanical stirrer, dropping funnel, condenser and nitrogen inlet). Tin(II) ethylhexanoate in $2 \mathrm{~mol} \%$ amount was used as catalyst. To prepare the prepolymer with isocyanate end-groups, $0.10 \mathrm{~g}$ $(97 \mu \mathrm{L}) \mathrm{HDI}\left(6 \times 10^{-4} \mathrm{~mol}, 2\right.$ equivalent $)$ was added to the reaction mixture and reacted for $2 \mathrm{~h}$ at $100-110^{\circ} \mathrm{C}$. To form the DA adduct, $0.06 \mathrm{~g}(53 \mu \mathrm{L}) \mathrm{FA}\left(6 \times 10^{-4} \mathrm{~mol}, 2\right.$ equivalent $)$ was added to the isocyanate-capped prepolymer solution in one portion at $100{ }^{\circ} \mathrm{C}$ and kept there for $1 \mathrm{~h}$. Afterwards, FA_DGEBA oligomer in toluene solution $\left(0.34 \mathrm{~g}, 3 \times 10^{-4} \mathrm{~mol}\right)$ and $0.11 \mathrm{~g}\left(3 \times 10^{-4} \mathrm{~mol}\right)$ BMI were added to the reaction mixture and stirred at $100-110^{\circ} \mathrm{C}$ for $1 \mathrm{~h}$. Accordingly, the composition of this 
EP-PU 16 sample is PCL(10)-HDI-FA-FA_DGEBA oligomer-BMI/1:2:2:1:1, where (10) refers to the $M_{n}$ of PCL expressed in $\mathrm{kg} / \mathrm{mol}$ unit. EP-PUs $17-24$ were synthesized according to the procedure described above. The corresponding molar ratios in the feed of the EP-PUs 16-24 synthesized are given in Table 2.

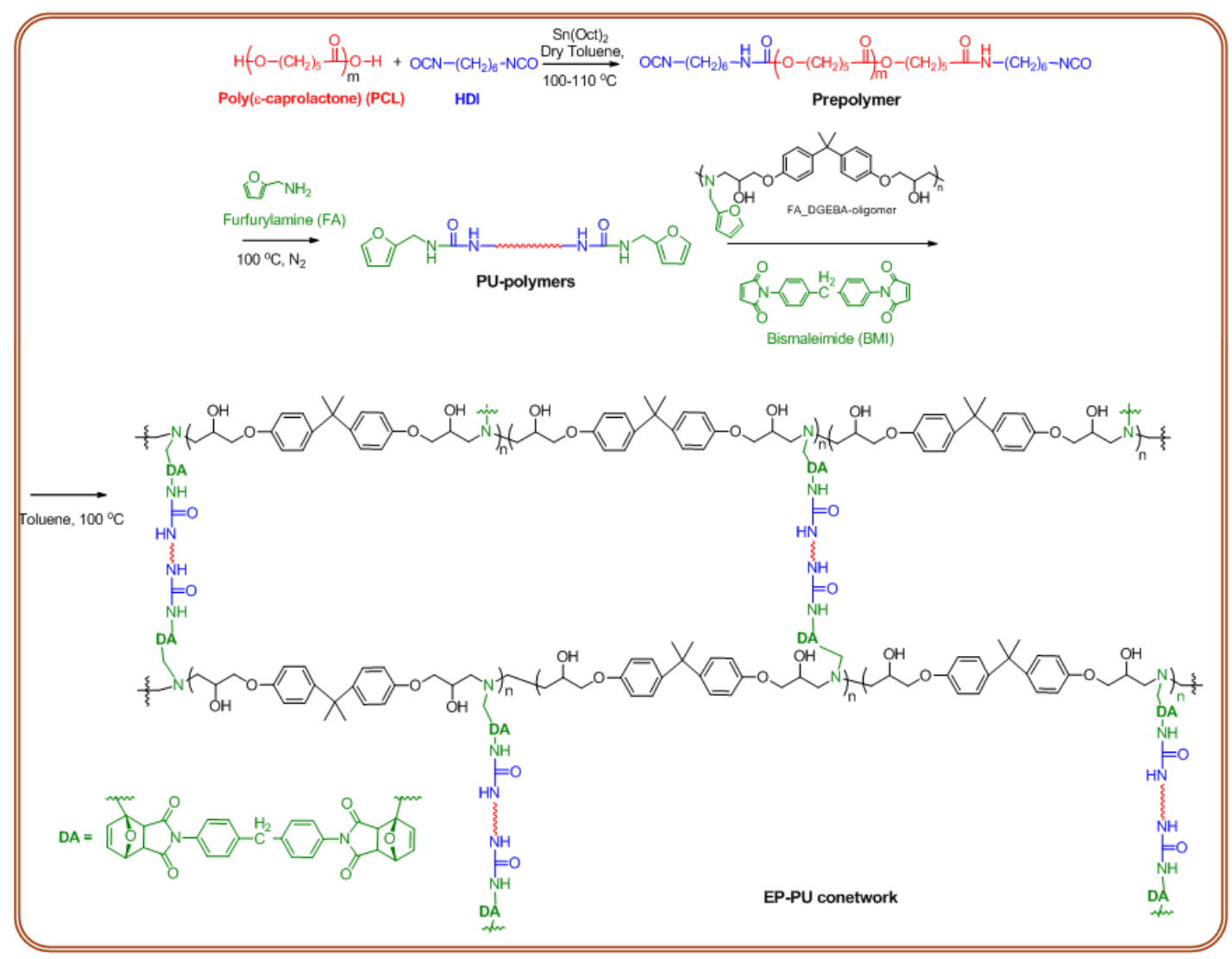

Scheme 2. Synthetic pathway for the preparation of samples EP-PU 16-24 containing DA-adducts.

Table 2. Composition and the corresponding molar ratios in the feed of the EP-PUs 16-24 synthesized. The number in the parenthesis represents the $M_{n}$ of the PCL expressed in $\mathrm{kg} / \mathrm{mol}$ unit.

\begin{tabular}{cc}
\hline Sample & Composition/Molar Ratios in the Feed \\
\hline EP-PU 16 17 & PCL(10)-HDI-FA-FA_DGEBA oligomer-BMI/1:2:2:1:1 \\
EP-PU 17 & PCL(10)-HDI-FA-FA_DGEBA oligomer-BMI/1:2:2:1:2 \\
EP-PU 18 & PCL(10)-HDI-FA-FA_DGEBA oligomer-BMI/1:2:2:2:1 \\
EP-PU 19 & PCL(10)-HDI-FA-FA_DGEBA oligomer-BMI/1:2:2:2.5:1 \\
EP-PU 20 & PCL(10)-HDI-FA-FA_DGEBA oligomer-BMI/1:2:2:3:1 \\
EP-PU 21 & PCL(50)-HDI-FA-FA_DGEBA oligomer-BMI $1: 2: 2: 5: 1$ \\
EP-PU 22 & PCL(50)-HDI-FA-FA_DGEBA oligomer-BMI / 1:2:2:10:1 \\
EP-PU 23 & PCL(50)-HDI-FA-FA_DGEBA oligomer-BMI/1:2:2:12.5:1 \\
EP-PU 24 & PCL(50)-HDI-FA-FA_DGEBA oligomer-BMI/1:2:2:15:1 \\
\hline
\end{tabular}

The mixtures containing the final EP-PU co-networks were poured onto Teflon ${ }^{\circledR}$ plates and dried in air resulting in elastic films.

\subsection{Characterization}

${ }^{1} \mathrm{H}$ NMR spectra were recorded with a Bruker AM $360\left(360 / 90 \mathrm{MHz}\right.$ for $\left.{ }^{1} \mathrm{H} /{ }^{13} \mathrm{C}\right)$ spectrometer (Karlsruhe, Germany). Deuterated chloroform was used as solvent. Chemical shifts were referenced to the ${ }^{1} \mathrm{H}$ signal of $\mathrm{Me}_{4} \mathrm{Si}$, which was used as standard. 
For the Matrix-Assisted Laser Desorption/Ionization Time-of-Flight Mass Spectrometry (MALDI-TOF MS) measurements a Bruker BIFLEX III ${ }^{\mathrm{TM}}$ mass spectrometer equipped with a time-of-flight (TOF) mass analyzer (Bremen, Germany) was used. In all cases, $19 \mathrm{kV}$ acceleration voltage was applied with pulsed ion extraction (PIE $\left.{ }^{\mathrm{TM}}\right)$. The ions were detected in the reflectron mode $(20 \mathrm{kV})$. A nitrogen laser $(337 \mathrm{~nm})$ operating at $4 \mathrm{~Hz}$ was used to produce laser desorption and 100 shots were summed. The MALDI-TOF MS spectra were externally calibrated with poly(ethylene glycol) standard $\left(M_{\mathrm{n}}=1540 \mathrm{~g} / \mathrm{mol}\right)$.

Samples for MALDI-TOF MS were prepared with 2,5-dihydroxy benzoic acid (DHB) matrix. The matrix was dissolved in tetrahydrofuran (THF) at a concentration of $20 \mathrm{mg} / \mathrm{mL}$. The matrix solution, the FA_DGEBA oligomer mixture $(10 \mu \mathrm{L}$ reaction mixture dissolved in $90 \mu \mathrm{L}$ THF and sodium trifluoroacetate solution $(5 \mathrm{mg} / \mathrm{mL}$ in THF) used as the cationization agent to promote the ionization) were mixed in a 10:2:1 $(v / v)$ ratio (matrix/analyte/cationization agent). A volume of $0.5 \mu \mathrm{L}$ of the solution was deposited onto a metal sample plate and allowed to air-dry.

Attenuated Total Reflectance (ATR) Fourier-Transform Infrared (ATR-FTIR) spectra were recorded on a Spectrum One FTIR spectrometer of PerkinElmer Instruments equipped with a Universal ATR Sampling Accessory (Waltham, MA, USA). The polymer was irradiated by IR beam through a special diamond-zinc-selenium composite prism. The penetration depth of the IR beam in the material is at about $6 \mu \mathrm{m}$. The average film thickness of the specimens was ca. $0.5 \mathrm{~mm}$. Four scans were taken for each sample. The spectra were evaluated by Spectrum ES 5.0 program (PerkinElmer, Waltham, MA, USA).

Instron 4302 type testing machine (Buckinghamsire, UK), equipped with a $1 \mathrm{kN}$ load cell, was used for tensile testing of the EP-PU series. At least three dumbbell specimens were cut (clamped length $60 \mathrm{~mm}$ ) from the film samples and tensile loaded at a strain rate $(\mathrm{d} \varepsilon / \mathrm{dt})$ of $0.025 / \mathrm{s}$.

The thermal properties of the synthesized PUs were examined by Differential Scanning Calorimetry (DSC). DSC tests were carried out in a DSC Q2000 power compensation equipment (TA Instruments, Hüllhorst, Germany) operating at $10{ }^{\circ} \mathrm{C} / \mathrm{min}$ heating rate. Nitrogen was used as protective atmosphere. The weight percentage of the crystalline PCL $\left(\mathrm{C}_{\mathrm{r}}(\%)\right)$ was calculated by Equation (3) [25]:

$$
C_{r}(\%)=\frac{\Delta H_{m}}{w_{A} \Delta H_{m}^{o}} \cdot 100
$$

where $\Delta H_{\mathrm{m}}$ is the heat of fusion of the PCL-containing PU, $w_{\mathrm{A}}$ is the weight fraction of PCL in the corresponding PU, and $\Delta H_{m}^{o}$ is the heat of fusion of the pure $100 \%$ crystalline PCL. For the latter, $135.31 \mathrm{~J} / \mathrm{g}$ has been taken from [26].

Dynamic Mechanical Analysis (DMA) testing of the PUs was carried out in a DMA Q800 device (TA Instruments, Hüllhorst, Germany). DMA traces were monitored in tension mode (dimension of the specimens: length: $25 \mathrm{~mm}$, clamped length: $12 \mathrm{~mm}$, width: $7 \mathrm{~mm}$, thickness: ca. $0.5 \mathrm{~mm}$ ) at an oscillation amplitude of $0.2 \%$ setting a frequency of $1 \mathrm{~Hz}$ and a static load of $1 \mathrm{~N}$. The temperature was varied between -50 and $200{ }^{\circ} \mathrm{C}$ with a heating rate of $3{ }^{\circ} \mathrm{C} / \mathrm{min}$.

Shape memory properties were determined in tensile mode using the aforementioned DMA device. The specimens (ca. $12 \times 7 \times 0.5 \mathrm{~mm}$ ) were stretched after $10 \mathrm{~min}$ holding at $60^{\circ} \mathrm{C}$ at a strain rate of $15 \% / \mathrm{min}$ to $30 \%$ strain, followed by a quick cooling to $20^{\circ} \mathrm{C}$ (cooling rate: $4.44{ }^{\circ} \mathrm{C} / \mathrm{min}$ ) and the shape fixity $\left(R_{\mathrm{f}}\right)$ was determined in $1 \mathrm{~min}$ after the stress had been released. Shape recovery $\left(R_{\mathrm{r}}\right)$ was measured at $0.1 \mathrm{~N}$ loading of the specimens (quasi free recovery) by reheating the specimens at $3{ }^{\circ} \mathrm{C} / \mathrm{min}$ heating rate from 20 to $60^{\circ} \mathrm{C}$ and holding there for $20 \mathrm{~min}$. The shape fixity $\left(R_{\mathrm{f}}\right)$ and shape recovery ratios $\left(R_{\mathrm{r}}\right)$ are determined according to Equations (4) and (5):

$$
\begin{gathered}
R_{f}(\%)=\frac{l_{d}-l_{o}}{l_{30 \%}-l_{o}} \cdot 100 \\
R_{r}(\%)=\frac{l_{d}-l_{f}}{l_{d}-l_{o}} \cdot 100
\end{gathered}
$$


where $l_{\mathrm{d}}$ is the sample length after removal of the tensile load during shape fixing at $20{ }^{\circ} \mathrm{C}, 1_{\mathrm{o}}$ is the clamped length of the sample at $20^{\circ} \mathrm{C}, l_{30}$ is the length after stretching the sample at $60^{\circ} \mathrm{C}$ in tensile load, and $l_{\mathrm{f}}$ is the final recovered length of the stretched specimen.

To get a deeper insight into the morphology Scanning Electron Microscopic (SEM) was adopted. SEM pictures were taken from the surface of selected specimens by a Hitachi S-4800 equipment (Tokyo, Japan). Surface of the specimens was covered with a $30 \mathrm{~nm}$ conductive gold layer.

\section{Results and Discussion}

In the syntheses of EP-PU 1-24, the $M_{n}$ of PCL, the amounts of DGEBA or FA_DGEBA oligomer, $\mathrm{BMI}$ and the HO-ended DA adduct were systematically varied to study their effects on the properties and morphologies of the resulting EP-PUs. Recall that two synthetic approaches were followed to prepare EP-PU co-networks. In the case of sample EP-PU 1-15 (see Table 1), the HO-ended DA adduct was incorporated as a thermoreversible connecting element between the isocyanate terminated polyurethane prepolymer and DGEBA, as depicted in Scheme 1. Furthermore, in the case of some EP-PU systems, crosslinking of EP was achieved using Jeffamine (JA) (EP-PU 10-15). In the second approach (see Table 2), the DA-adduct was obtained "in situ" through the reaction between the furanyl- and maleimide-containing prepolymers, as shown in Scheme 2. The latter was obtained by the reaction of isocyanate functionalized prepolymer with FA (see Figure 2). To link the FA-end-functionalized prepolymers to the FA_DGEBA oligomer, BMI was added to the reaction mixture, which led to formation of the DA-adducts (see EP-PU 16-24). It is noteworthy that only selected EP-PU samples were subjected to some investigations to keep this contribution in limits. However, peculiar attention was paid to their selection to obtain information on effects of relevant compositional/structural variables.

\subsection{Infrared Spectroscopy of the EP-Networks}

Figure 3 shows the ATR-FTIR spectra of the representative samples EP-PU 2, 4, 5, 6, 8, 9 and 16.

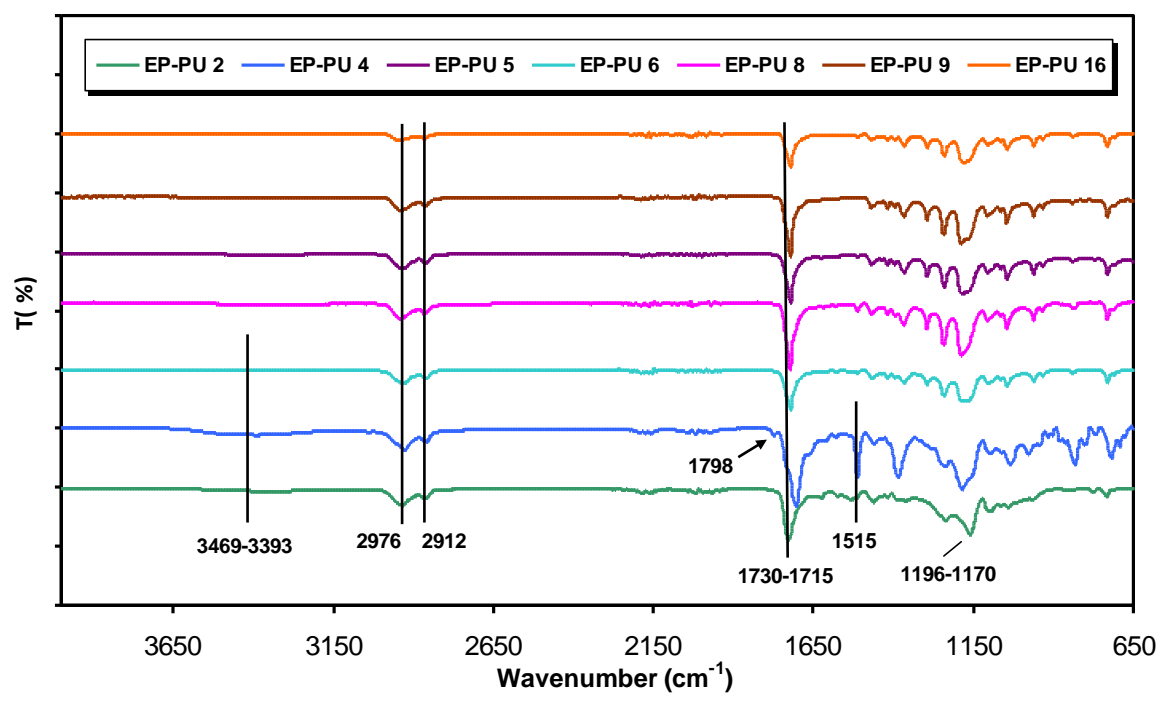

Figure 3. ATR-FTIR spectra of EP-PUs 2, 4, 5, 6, 8, 9 and 16.

In the case of EP-PU samples with PCL of lower molecular weight (e.g., EP-PU 2 and 4), the NH band of urethane can be detected at $3393-3469 \mathrm{~cm}^{-1}$ as a broad absorption. The absorption bands at 2912 and $2976 \mathrm{~cm}^{-1}$ and at $1362 \mathrm{~cm}^{-1}$ belong to the symmetric and asymmetric $\mathrm{CH}_{2}$ stretching and bending vibrations, respectively. The lack of absorption band at around $2230 \mathrm{~cm}^{-1}$, which is characteristics of the NCO group, indicates the complete transformation of the NCO end groups. The $\mathrm{C}=\mathrm{O}$ band of EP-PUs is visible at $1715-1730 \mathrm{~cm}^{-1}$, which suggests that there is no considerable 
hydrogen bond interaction. In the FTIR spectra of PUs, the H-bonded C=O band should appear at 1684 and $1690 \mathrm{~cm}^{-1}$ [27].

The weak absorption band at $1798 \mathrm{~cm}^{-1}$ ( $\mathrm{C}=\mathrm{O}$ of maleimide part) appeared only in the FTIR spectrum of EP-PU 4 indicating the presence of the DA adduct [23]. Moreover, in the case of EP-PU samples prepared with higher molecular weight PCLs (e.g., 10, 25 and $50 \mathrm{~kg} / \mathrm{mol}$ ), this band is not visible. Another intriguing finding is the presence of a band at $1515 \mathrm{~cm}^{-1}$, which may be associated with the amide II band for poly(ester-ether urethane) [28]. This band occurred with much higher intensity for the sample EP-PU 4 than for other PU samples. The band at $\sim 1196-1170 \mathrm{~cm}^{-1}$ with relatively high intensity was assigned to the $=\mathrm{C}-\mathrm{O} /-\mathrm{C}-\mathrm{O}-\mathrm{C}-$ vibrations which appeared as a sharp peak in the FTIR spectrum of EP-PU 2 [29].

\subsection{Thermal Behavior}

The thermal behaviors of the EP-PU samples were investigated by DSC. Some typical DSC traces for the EP-PU samples are shown in Figure 4 and the related results listed in Table 3.

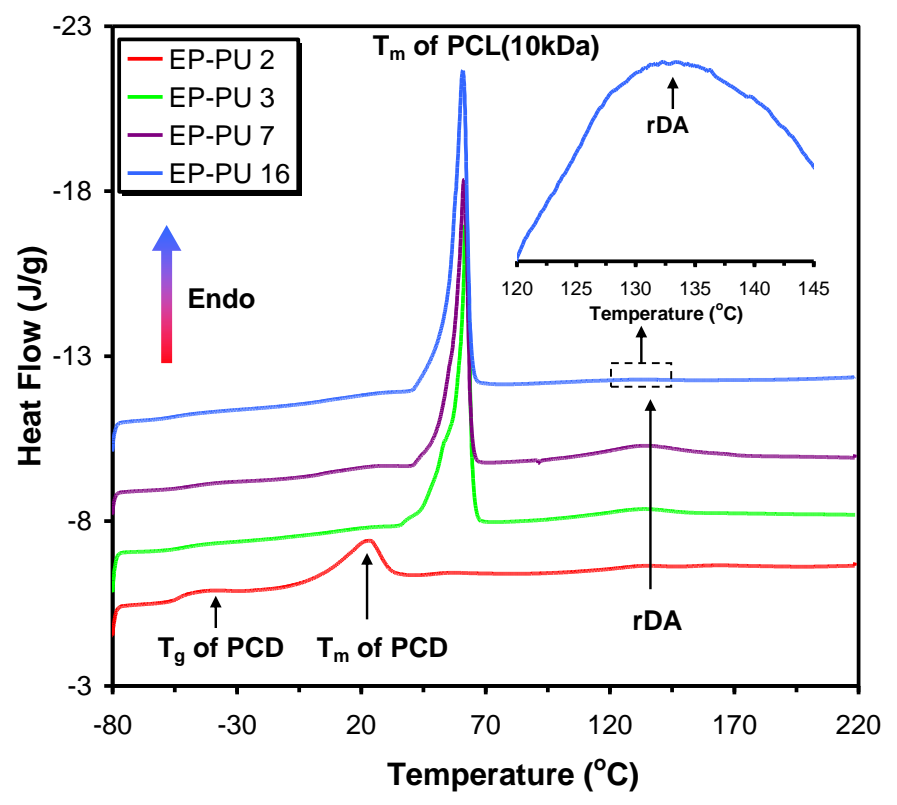

Figure 4. DSC curves of EP-PUs 2, 3, 7 and 16. The inset shows the zoomed part of the DSC trace for the sample EP-PU 16 in the temperature range of $120-145^{\circ} \mathrm{C}$.

Table 3. Glass transition temperature $\left(T_{\mathrm{g}}\right)$, melting temperature $\left(T_{\mathrm{m}}\right)$, melting enthalpy $\left(\Delta H_{\mathrm{m}}\right)$, crystallinity values and rDA temperatures from DSC measurements in the first heating cycle.

\begin{tabular}{cccccc}
\hline Sample & $\boldsymbol{T}_{\mathbf{g}}\left({ }^{\circ} \mathbf{C}\right)$ & $\boldsymbol{T}_{\mathbf{m}}\left({ }^{\circ} \mathbf{C}\right)$ & $\Delta \boldsymbol{H}_{\mathbf{m}}(\mathbf{J} / \mathbf{g})$ & Crystallinity $(\%)$ & rDA $\left({ }^{\circ} \mathbf{C}\right)$ \\
\hline EP-PU 1 & -48.4 & 23.8 & 9.8 & 10.1 & 133.9 \\
EP-PU 2 & -53.1 & 22.9 & 19.4 & 23.3 & 136.8 \\
EP-PU 3 & - & 61.7 & 67.8 & 56.3 & 134.6 \\
EP-PU 4 & - & 65.3 & 89.95 & 69.7 & 139.8 \\
EP-PU 6 & -41.7 & 20.3 & 3.7 & 5.7 & 138.4 \\
EP-PU 7 & - & 61.3 & 67.6 & 60.7 & 135.3 \\
EP-PU 10 & - & 61.8 & 57.8 & 48.4 & 133.3 \\
EP-PU 11 & - & 63.2 & 73.1 & 56.9 & 136.4 \\
EP-PU 13 & - & 61.6 & 54.9 & 50.0 & 132.7 \\
EP-PU 16 & - & 60.9 & 64.2 & 58.6 & 133.7 \\
EP-PU 17 & - & 62.8 & 67.4 & 61.5 & 131.1 \\
EP-PU 18 & - & 62.2 & 67.0 & 66.5 & 130.8 \\
EP-PU 20 & - & 61.3 & 58.6 & 64.6 & 128.9 \\
\hline
\end{tabular}


According to Figure 4 and the data in Table 3 , the glass transition temperature $\left(T_{\mathrm{g}}\right)$ of the samples containing PCD with $M_{\mathrm{n}}=2 \mathrm{~kg} / \mathrm{mol}$ appears in the range from -50 to $-40{ }^{\circ} \mathrm{C}$, while $T_{\mathrm{m}}$ values are around $20^{\circ} \mathrm{C}$ (see Table 3). However, $\mathrm{T}_{\mathrm{m}}$-s of higher molecular weight PCL segments (e.g., $M_{\mathrm{n}}=10 \mathrm{~kg} / \mathrm{mol}$ ) appear at around $60^{\circ} \mathrm{C}$, which is in good agreement with former works on PUs with PCL segments [30,31]. In the case of samples with increasing EP contents (see EP-PU 2 and 6), the $\Delta H_{\mathrm{m}}$, and thus the crystallinity values, decreased considerably. Moreover, the degree of crystallinity also decreased with crosslinking of EP. This can be traced to the fact that crosslinking reduces the flexibility of PCL segments and thus decreases the crystallizable fraction of PCL in these samples (see EP-PU 3 vs. EP-PU 10 and EP-PU 7 vs. EP-PU 13 and EP-PU 4 vs. EP-PU 11). An important result of the DSC tests was that, besides the $\mathrm{T}_{\mathrm{g}}$ and $\mathrm{T}_{\mathrm{m}}$, a broad endothermic peak could be resolved in DSC traces in the temperature range $110-145{ }^{\circ} \mathrm{C}$ (see EP-PU 2, 3, 7 and 16). This was assigned to the retro-DA $(\mathrm{rDA})$ reaction.

\subsection{Morphology}

As seen in Figure 5 the morphology considerably changed by the synthetic method and chemical composition applied for the preparation of these samples. For example, the morphology of samples EP-PU 2, 3, 6, 16, 18 and 20 seems to be more uniform, than those of EP-PUs 7, 8 and 9. Furthermore, with increasing amount of the EP component, a "voided" structure was formed, which might be caused by a strong microphase separation in the co-networks. This structural feature becomes more pronounced with increasing molecular weight of PCL segments (see, e.g., EP-PUs 6-9).

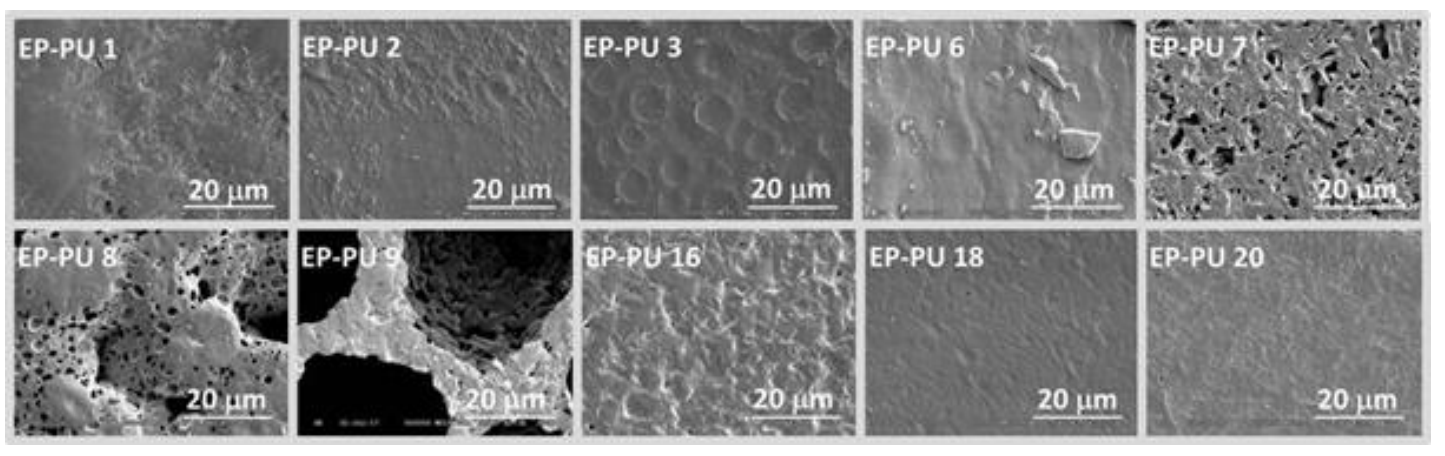

Figure 5. SEM images of samples EP-PU 1, 2, 3, 6, 7, 8, 9, 16, 18 and 20.

\subsection{Tensile Properties}

The results of tensile tests of the samples prepared by the two synthetic approaches are presented in Tables 4 and 5.

The data in Table 4 indicate that EP-PU samples prepared with the low molecular weight PCD $(2 \mathrm{~kg} / \mathrm{mol})$ exhibit low E-moduli and relatively high elongation at break values (see EP-PU 2 and 6). Furthermore, it can be noticed that the $\mathrm{M}_{\mathrm{n}}$ of the PCL also greatly affected the mechanical properties, especially the E-modulus. Samples with the highest E-moduli were obtained with PCL of $M_{n}=25$ and $50 \mathrm{~kg} / \mathrm{mol}$, respectively (see samples EP-PU 4 and EP-PU 5). Interestingly, incorporation of higher amount of DA adducts into the EP-PU system yielded lower stiffness (E-modulus), tensile strength and elongation at break values (compare e.g., EP-PU 2 with EP-PU 6, EP-PU 3 with EP-PU 7, EP-PU 4 with EP-PU 8). This tendency can be attributed to the fact that, in the presence of higher amount of DA-adducts, shorter-DA-PU- chains were formed. It has to be underlined that crosslinking trough the remaining epoxy groups with a polyether amine (Jeffamine ${ }^{\circledR}$ EDR 176) yielded co-networks whose E-moduli and tensile strength were higher than those of their non-crosslinked counterparts (compare EP-PU 7 with EP-PU 13 and EP-PU 4 with EP-PU 11). 
Table 4. Tensile mechanical properties of the EP-PUs 1-15. Designations: E, elastic modulus; $\varepsilon_{\mathrm{R}}$, ultimate elongation; $\sigma_{R}$, stress at break.

\begin{tabular}{cccc}
\hline Sample & $\boldsymbol{E} \mathbf{( M P a )}$ & $\boldsymbol{\varepsilon}_{\mathbf{R}} \mathbf{( \% )}$ & $\left.\boldsymbol{\sigma}_{\mathbf{R}} \mathbf{( M P a}\right)$ \\
\hline EP-PU 1 & $2 \pm 0.2$ & $837 \pm 26$ & $17 \pm 2$ \\
EP-PU 2 & $4 \pm 1$ & $627.5 \pm 77$ & $20 \pm 2$ \\
EP-PU 3 & $177 \pm 14$ & $974 \pm 76$ & $27 \pm 3$ \\
EP-PU 4 & $233 \pm 5$ & $4 \pm 0.2$ & $7.5 \pm 0.5$ \\
EP-PU 5 & $181 \pm 12$ & $794.5 \pm 50$ & $20 \pm 3$ \\
EP-PU 6 & $1 \pm 0.2$ & $910 \pm 31$ & $9 \pm 1$ \\
EP-PU 7 & $107 \pm 10$ & $30 \pm 5$ & $7 \pm 0.2$ \\
EP-PU 8 & $184 \pm 13$ & $5 \pm 1$ & $3 \pm 1$ \\
EP-PU 9 & $92 \pm 16$ & $298 \pm 30$ & $8.2 \pm 0.5$ \\
EP-PU 10 & $232 \pm 5$ & $457 \pm 63$ & $25 \pm 1$ \\
EP-PU 11 & $237 \pm 29$ & $907.5 \pm 6$ & $17 \pm 1$ \\
EP-PU 12 & $349 \pm 20$ & $604.5 \pm 31$ & $35 \pm 0.3$ \\
EP-PU 13 & $221 \pm 29$ & $243.5 \pm 35$ & $22.5 \pm 0.7$ \\
EP-PU 14 & $124.5 \pm 16$ & $549 \pm 65$ & $21 \pm 1$ \\
EP-PU 15 & $208 \pm 19$ & & \\
\hline
\end{tabular}

Table 5. Tensile mechanical properties of EP-PUs 16-24. For designations, see Table 4.

\begin{tabular}{cccc}
\hline Sample & $\boldsymbol{E} \mathbf{( M P a )}$ & $\boldsymbol{\varepsilon}_{\mathbf{R}} \mathbf{( \% )}$ & $\boldsymbol{\sigma}_{\mathbf{R}} \mathbf{( M P a )}$ \\
\hline EP-PU 16 & $387 \pm 10$ & $670 \pm 113$ & $22 \pm 3$ \\
EP-PU 17 & $388 \pm 98$ & $378 \pm 83$ & $21 \pm 1$ \\
EP-PU 18 & $392 \pm 6$ & $359 \pm 8$ & $14 \pm 3$ \\
EP-PU 19 & $470 \pm 107$ & $2 \pm 0.3$ & $10 \pm 2$ \\
EP-PU 20 & $648.5 \pm 47$ & $3.5 \pm 0.5$ & $15 \pm 2$ \\
EP-PU 21 & $477 \pm 51.5$ & $419 \pm 42$ & $23 \pm 1$ \\
EP-PU 22 & $366 \pm 31$ & $11 \pm 2$ & $13 \pm 0.3$ \\
EP-PU 23 & $294 \pm 66$ & $9 \pm 1.4$ & $10 \pm 1$ \\
EP-PU 24 & $305 \pm 24$ & $11.5 \pm 3$ & $11 \pm 0.3$ \\
\hline
\end{tabular}

Although the mechanical properties of the EP-PU systems prepared by the second synthetic approach (i.e., containing polymerized EP resin and DA adducts) do not show clear trends, some important conclusions can be drawn from the data in Table 5: (i) at low EP resin content, the increasing amount of the DA coupling agent considerably reduced the elongation at break (see samples EP-PU 16 and EP-PU 17); (ii) increase in the amount of EP resin in the samples prepared with PCL of $M_{\mathrm{n}}=10 \mathrm{~kg} / \mathrm{mol}$ resulted in higher E-moduli (see samples EP-PU 16-20), while an opposite trend can be observed for the samples with PCL of $M_{\mathrm{n}}=50 \mathrm{~kg} / \mathrm{mol}$ (see samples EP-PU 21 to 24); (iii) the elongation at break decreased with increasing EP content and with the $\mathrm{M}_{n}$ of PCL; and (iv) the E-moduli are higher and the elongations at break values for the EP-PUs prepared by the second synthetic route (Scheme 2) are lower than those prepared by the first one (Scheme 1).

The stress-strain curves for samples prepared with low molecular weight PCD $\left(M_{\mathrm{n}}=2 \mathrm{~kg} / \mathrm{mol}\right)$ and PCL $\left(M_{n}=10 \mathrm{~kg} / \mathrm{mol}\right)$ resembled to those of elastomers while samples made with PCL of higher $M_{\mathrm{n}}$ or prepared by the second synthetic approach showed tensile characteristics similar to those of flexible plastics.

\subsection{Modeling the Stress-Strain Behavior the EP-PU Co-networks}

In the following, it will be shown that the observed stress-strain curves for some synthesized EP-PU samples having more uniform micromorphologies (EP-PU 1 and 2) can be adequately described using the Standard Linear Solid (SLS) rheological model presented in Figure 6. 


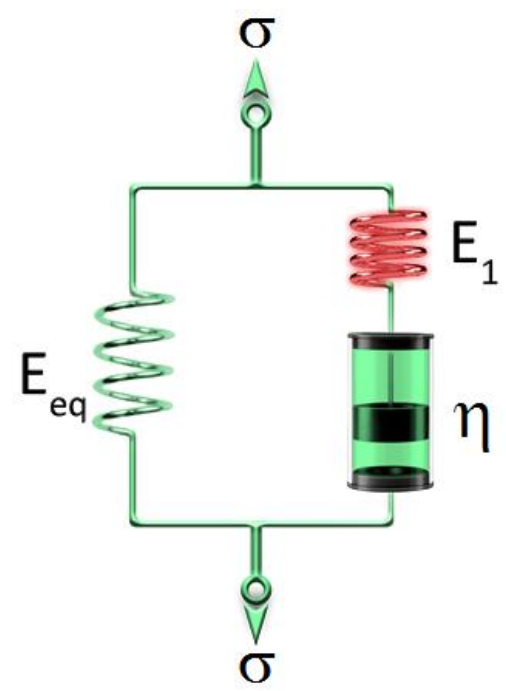

Figure 6. The Standard Linear Solid (SLS) model. $E_{\text {eq }}$ and $E_{1}$ represent the equilibrium (rubbery) and the non-equilibrium (glassy) spring modulus, respectively, while $\eta$ stands for the dynamic viscosity of the liquid in the dashpot.

According to this model, the relationship between the stress $(\sigma)$ and the strain $(\varepsilon)$ as well as their derivatives with respect to time are given by Equation (6) [32]

$$
\sigma+a_{1} \frac{d \sigma}{d t}=a_{2} \varepsilon+a_{3} \frac{d \varepsilon}{d t}
$$

where $a_{1}=\eta / E_{1} ; a_{2}=E_{\mathrm{eq}} ;$ and $a_{3}=\eta\left(1+E_{\mathrm{eq}} / E_{1}\right)$

In uniaxial tensile experiments, the strain rate $(d \varepsilon / d t)$ was kept constant, thus Equation (6) can be rewritten to obtain Equation (7):

$$
\sigma+a_{1}\left(\frac{d \varepsilon}{d t}\right) \frac{d \sigma}{d \varepsilon}=a_{2} \varepsilon+a_{3} \frac{d \varepsilon}{d t}
$$

Integrating Equation (7) yields Equation (8), which establishes a relationship between the stress $(\sigma)$ and strain $(\varepsilon)$ at a constant strain rate.

$$
\sigma=b_{1}\left[\varepsilon+b_{2}\left(1-e^{-b_{3} \varepsilon}\right)\right]
$$

where $b_{1}=a_{2}, b_{2}=(d \varepsilon / d t)\left(a_{3} / a_{2}-a_{1}\right)$ and $b_{3}=\frac{1}{(d \varepsilon / d t) a_{1}}$.

Parameters $b_{1}, b_{2}$ and $b_{3}$ were obtained by fitting Equation (8) to the corresponding experimental $\sigma-\varepsilon$ data points. As evident from Figure 7a, Equation (7) describes the stress-strain curves accurately up to moderate strain values.

On the other hand, it can also be concluded from Figure 7a and the fitted parameters that increasing the molar ratio of the Diels-Alder adduct from 0.5:0.5 to 1:1 (compare EP-PU 1 with EP-PU 2) results in the increase of parameters $b_{1}, b_{2}$ and $b_{3}$. This indicates an increase in the E-modulus and $a$ steeper dependence of $\sigma$ on $\varepsilon$. This finding can be ascribed to a higher crosslink density in the case of EP-PU 2. As demonstrated above, the relatively simple SLS model describes accurately the stress-strain relationship up to moderately high strains, however, it fails at high strains due to the considerable upward curvature of the $\sigma$ vs. $\varepsilon$ traces. Because the latter feature should be linked with strain-induced crystallization, it has to be considered to describe the $\sigma-\varepsilon$ curves at high strains. Therefore, it was assumed that, after a certain strain $\left(\varepsilon_{L}\right)$, strain-induced orientation/crystallization takes place, which 
manifests in an increased value of $E_{\text {eq, }}$, i.e., in the value of $\mathrm{a}_{2}(\varepsilon)$ parameter, as shown by Equation ( $\left.9 \mathrm{a}\right)$ and Equation $(9 b)$.

$$
\begin{gathered}
a_{2}(\varepsilon)=a_{2}\left(\text { if } \varepsilon \leq \varepsilon_{L}\right) \\
a_{2}(\varepsilon)=a_{2}+\alpha\left(\varepsilon-\varepsilon_{L}\right)\left(\text { if } \varepsilon>\varepsilon_{L}\right)
\end{gathered}
$$

where $a_{2}$ is the value of $a_{2}(\varepsilon)$ up to the onset of curvature of the $\sigma-\varepsilon$ curve and $\alpha$ is a proportionality constant.
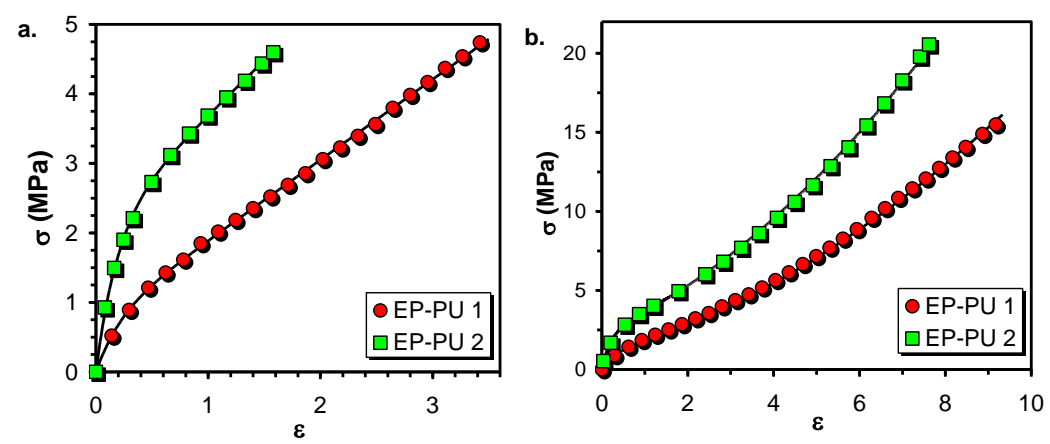

Figure 7. Stress-strain curves for the samples EP-PUs 1 and 2: up to moderate strains (a); and up to elongation at break (b). The symbols and the solid lines represent the experimental data and the fitted curves, respectively. The fitted parameters for the sample EP-PU 1 are $b_{1}=1.16 \mathrm{MPa}, b_{2}=0.63$ and $b_{3}=4.73$ (i.e., $(d \varepsilon / d t) a_{1}=0.21, a_{2}=1.16 \mathrm{MPa},(d \varepsilon / d t) a_{3}=0.97 \mathrm{MPa}$ and $\left.\alpha=0.089 \mathrm{MPa}\right)$, while for the sample EP-PU 2 these parameters are $b_{1}=1.57 \mathrm{MPa}, b_{2}=1.36$ and $b_{3}=5.17$ (i.e., $\left.d \varepsilon / d t\right) a_{1}=0.19$, $a_{2}=1.57 \mathrm{MPa},(d \varepsilon / d t) a_{3}=2.44 \mathrm{MPa}$ and $\left.\alpha=0.15 \mathrm{MPa}\right)$.

After an appropriate rearrangement of Equation (6) and using Equation (9b), we get the following equation:

$$
\frac{d \sigma}{d \varepsilon}=\frac{1}{a_{1} \frac{d \varepsilon}{d t}}\left(a_{2}(\varepsilon) \varepsilon+a_{3} \frac{d \varepsilon}{d t}-\sigma\right)
$$

Equation (10) was integrated numerically and fitted to the whole $\sigma-\varepsilon$ curves (up to break) to obtain parameter $\alpha$. It should be noted, however, that, for fitting to the whole curve, parameters $\mathrm{a}_{1}, \mathrm{a}_{2}$ and $\mathrm{a}_{3}$ were used as determined from the $\sigma-\varepsilon$ curves up to moderately strains and only parameter $\alpha$ was that one which was obtained by fitting of Equation (10).

As seen in Figure 7b, the extended SLS model (Equation (10)) is capable of describing the $\sigma$ vs. $\varepsilon$ relationship for the EP-PU systems in a wide range of $\varepsilon$ values.

\subsection{DMA Analysis}

Thermomechanical behavior of samples EP-PUs was also studied using dynamic mechanical analysis (DMA) in tensile mode. Storage modulus as a function of temperature for samples EP-PU 2, 3, 6 and EP-PU 13 are depicted in Figure 8. The crosslink densities $\left(v_{\mathrm{e}}\right)$ were calculated by Equation (11) and are summarized in Table 6.

$$
v_{\mathrm{e}}=\frac{E^{\prime}}{3 R T}
$$

where $E^{\prime}, R$ and $T$ are the storage modulus, the universal gas-constant and the temperature at the onset of the rubbery state, respectively. Since no clear rubbery plateau appeared, the $E^{\prime}$ was read at the onset temperature of the rubbery state (cf. Table 6). 


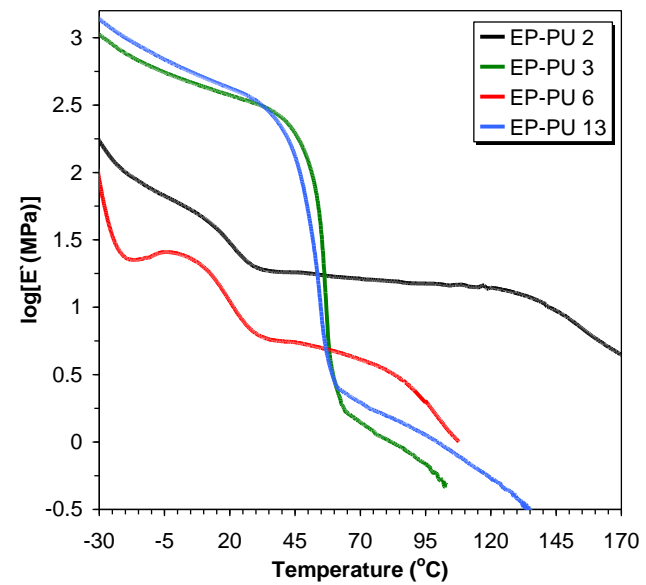

Figure 8. Storage modulus as a function of temperature for samples EP-PU 2, 3, 6, and 13.

Table 6. The $E^{\prime}$ values and crosslink densities $\left(v_{\mathrm{e}}\right)$ obtained from DMA results for samples EP-PU 2, 3 , 6 and EP-PU 13. The temperature in the bracket after the value of $v_{\mathrm{e}}$ is the rubbery onset temperature considered in the calculation.

\begin{tabular}{ccc}
\hline Sample & $E^{\prime}(\mathbf{M P a})$ & $v_{\mathbf{e}}\left(\mathbf{m o L} / \mathrm{cm}^{3}\right)$ \\
\hline EP-PU 2 & 18.2 & $2.3 \times 10^{-3}\left(40^{\circ} \mathrm{C}\right)$ \\
EP-PU 3 & 1.5 & $1.8 \times 10^{-4}\left(67^{\circ} \mathrm{C}\right)$ \\
EP-PU 6 & 5.6 & $7.2 \times 10^{-4}\left(40^{\circ} \mathrm{C}\right)$ \\
EP-PU 13 & 2.2 & $2.6 \times 10^{-4}\left(65^{\circ} \mathrm{C}\right)$ \\
\hline
\end{tabular}

As shown in Figure 8., the storage modulus decreased $\left(E^{\prime}\right)$ considerably at $20-22{ }^{\circ} \mathrm{C}$ for EP-PU 2 and EP-PU 6, while for the sample EP-PU 3 (containing crystalline PCL) E' decreased sharply only at $60-65{ }^{\circ} \mathrm{C}$ due to the melting of the crystalline PCL phase. It is noteworthy that well developed rubbery plateau, attributable to the presence of a crosslinked network, was rarely observed (e.g., EP-PU 2). Instead, the $E^{\prime}$ was reduced with increasing temperature featuring a leathery transition. The width of the latter decreased with increasing molar ratio of EP to PU (compare the DMA curve of EP-PU 2 and EP-PU 6). The $E^{\prime}$ decrease in the rubbery plateau/leathery region reflects most likely the advancing $\mathrm{rDA}$ reaction. The rDA process lowers the crosslink density and/or the segments lengths between the netpoints, thus yielding lower $\mathrm{E}^{\prime}$ values.

\subsection{Shape Memory Experiments}

The SM characteristics, i.e., the values of shape fixity $\left(R_{\mathrm{f}}\right)$ and shape recovery ratios $\left(R_{\mathrm{r}}\right)$, are given in Table 7. As shown in the data in Table 7, the shape fixity ratios are very close to $100 \%$ for samples EP-PU3, EP-PU 10 and EP-PU13. The high values of $R_{\mathrm{f}}$ can be traced to the significant difference in the "glassy" and the "rubbery" moduli [32-34]. However, poor shape fixity ratios were found for EP-PU 2 most likely due to the low melting temperature of the PCD segments (cf. Table 3). On the other hand, decreasing the shape fixity temperature from 20 to $0{ }^{\circ} \mathrm{C}$ for sample EP-PU 2 results in a better $\mathrm{R}_{\mathrm{f}}$ value. The related original DMA traces registered during SM programing of EP-PU 2, i.e., temperature, stress and strain as a function of time, are given in the Supplementary Materials (see Figures S1 and S2, respectively). In the Supplementary Materials, we have also included the original SM cycles for EP-PU 3 (Figure S3) and EP-PU 10 (Figure S4) to demonstrate effects of the additional crosslinking with Jeffamine (JA, see Table 1). Note that, except for EP-PU 2, rather high $R_{\mathrm{r}}$ values were measured for all other tested samples.

Since the recovery process plays an important role in the function of shape memory polymers, an attempt was made to describe the relationship between the strain $(\varepsilon)$ and the recovery time $(t)$. It 
was found that the strain as a function of time can be fairly described by means of a double exponential decay function as shown by Equation (12). Note that this approach was suited to describe the strain recovery also for another PU system [34]:

$$
\varepsilon(t)=A_{1} e^{\frac{-\left(t-t_{0}\right)}{\tau_{1}}}+A_{2} e^{\frac{-\left(t-t_{0}\right)}{\tau_{2}}}
$$

where $\varepsilon(t)$ is the strain, $A_{1}$ and $A_{2}$ are amplitudes (pre-exponential factors), $\tau_{1}$ and $\tau_{2}$ represent relaxation times, and $t_{\mathrm{o}}$ is the onset of shape recovery (accordingly, $t \leq t_{\mathrm{o}}$ is the valid range).

Table 7. Shape fixity and shape recovery ratios for selected EP-PUs.

\begin{tabular}{ccc}
\hline Sample & $\boldsymbol{R}_{\mathbf{f}}(\mathbf{\%})$ & $\boldsymbol{R}_{\mathbf{r}}(\mathbf{\%})$ \\
\hline EP-PU 2 & 35 & 77 \\
& $63^{*}$ & $88^{*}$ \\
\hline EP-PU 3 & 99 & 83 \\
EP-PU 10 & 99 & 84 \\
EP-PU 13 & 98 & 85 \\
\hline
\end{tabular}

* Shape fixed at $0{ }^{\circ} \mathrm{C}$.

In Figure 9, the close isothermal free recovery as a function of time for the samples EP-PU 3 and 13 are plotted.

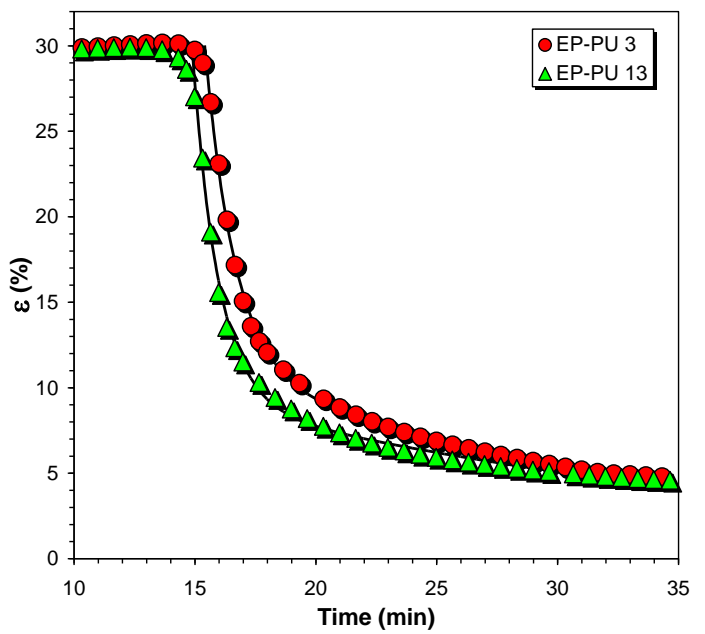

Figure 9. Free recovery curves for the EP-PU 3 and EP-PU 13 samples. The symbols and solid lines represent the experimental data and the fitted curves calculated using double exponential functions, respectively. The fitting parameters of the curves are: $A_{1}=18.6, \tau_{1}=1.23 \mathrm{~min}^{-1}$ and $A_{2}=11.0$, $\tau_{2}=21.2 \mathrm{~min}^{-1}$ for the EP-PU 3, $A_{1}=17.1, \tau_{1}=1.1 \mathrm{~min}^{-1}$ and $A_{2}=9.2, \tau_{2}=25.0 \mathrm{~min}^{-1}$ for the EP-PU 13.

As confirmed in Figure 9, Equation (12) describes the variation of strain with time adequately. The first, relatively fast, relaxation $\left(\tau_{1}\right)$ can be ascribed to the strain release due to the rapid melting of the crystalline PCL segment, while the second, much slower, relaxation process $\left(\tau_{2}\right)$ is most likely linked with the time required for polymer chains to return to their original conformations [34].

\section{Conclusions}

EP-PU co-networks containing PCL and DA adducts were prepared using two different synthetic strategies. The first synthetic way for the preparation of samples EP-PU 1-15 was the incorporation of a HO-ended DA adduct in the networks composed of isocyanate (HDI) terminated 
polyurethane prepolymer and DGEBA and followed by crosslinking of the EP-component by polyetheramine (Jeffamine ${ }^{\circledR}$ EDR 176). The other synthetic route utilized the reaction between furanyl end-functionalized PU polymers and FA_DGEBA oligomer in the presence of BMI as the coupling agent (samples EP-PU 16-24). Thus, the two synthetic routes differed from one another in generation of the DA-adducts and in the composition of the co-networks. The morphology of the EP-PU samples, investigated by SEM, also varied with the composition and the synthetic method. The presence of the DA adducts in the EP-PU samples synthesized was supported by ATR-FTIR and DSC measurements. According to the results of DMA, above $T_{\mathrm{m}}$ of the PCL, a rubbery plateau or a leathery region was obtained for the EP-PU samples. It was proposed that the incorporated DA-adducts provide an additional switch via rDA reactions in addition to the crystalline PCL segments, carrying a possibility for additional shape memory programming. The stress-strain curves of the EP-PU samples could be well approximated by the simple SLS model up to moderately low strains. By incorporating a strain-induced crystallization term, the validity range of the SLS model could be expanded for high strains, as well. It has also been shown that the free recovery process in shape memory tests of the EP-PU samples can adequately be described by double exponential decay functions including fast and slow relaxation modes.

These novel EP-PU co-networked systems containing reversible DA-linkages may find their applications among the well-tuned $\mathrm{T}_{\mathrm{m}}$-based shape memory and self-healing polymers.

Supplementary Materials: Supplementary materials are available online at http:/ /www.mdpi.com/2073-4360/ 10/5/504/s1.

Author Contributions: K.C., S.K., J.K.-K. and M.Z. conceived and designed the experiments; C.K. and L.C. performed the experiments; L.D. performed the SEM investigations; C.K., L.C., S.K. and J.K.-K. analyzed the data; and K.C., S.K., J.K.-K. and M.Z. wrote the paper.

Acknowledgments: This work was supported by the GINOP-2.3.2-15-2016-00041 and GINOP-2.3.3-15-2016-00021 projects. The projects were co-financed by the European Union and the European Regional Development Fund.

Conflicts of Interest: The authors declare no conflict of interest.

\section{References}

1. Rolere, S.; Coulon, J.-F.; Poncin-Epaillard, F. Influence of the curing temperature on the diffusion rate of the perfluorinated alkyl chains of a modified epoxy resin. Eur. Polym. J. 2017, 91, 61-69. [CrossRef]

2. Bakar, M.; Hausnerova, B.; Kostrzewa, M. Effect of diisocyanates on the properties and morphology of epoxy/polyurethane interpenetrating polymer networks. J. Therm. Comp. Mat. 2013, 26, 1364-1376. [CrossRef]

3. Park, C.-H.; Lee, S.-W.; Park, J.-W.; Kim, H.-J. Preparation and characterization of dual curable adhesives containing epoxy and acrylate functionalities. React. Funct. Polym. 2013, 73, 641-646. [CrossRef]

4. Jin, H.; Miller, G.M.; Pety, S.J.; Griffin, A.S.; Stradley, D.S.; Roach, D.; Sottos, N.R.; White, S.R. Fracture behavior of a self-healing, toughened epoxy adhesive. Int. J. Adhes. Adhes. 2013, 44, 157-165. [CrossRef]

5. Reghunadhan, A.; Datta, J.; Kalarikkal, N.; Thomas, S. Development of nanoscale morphology and role of viscoelastic phase separation on the properties of epoxy/recycled polyurethane blends. Polymer 2017, 117, 96-106. [CrossRef]

6. Rosu, D.; Rosu, L.; Mustata, F.; Varganici, C.-D. Effect of UV radiation on some semi-interpenetrating polymer networks based on polyurethane and epoxy resin. Polym. Degrad. Stab. 2012, 97, 1261-1269. [CrossRef]

7. Frisch, H.L.; Frisch, K.C.; Klempner, D. Glass transitions of topologically interpenetrating polymer networks. Polym. Eng. Sci. 1974, 14, 646-650. [CrossRef]

8. Sun, W.; Yan, X.; Zhu, X. The synthetic kinetics and underwater acoustic absorption properties of novel epoxyurethanes and their blends with epoxy resin. Polym. Bull. 2012, 69, 621-633. [CrossRef]

9. Hsieh, K.H.; Han, J.L.; Yu, C.T.; Fu, S.C. Graft interpenetrating polymer networks of urethane-modified bismaleimide and epoxy (I): Mechanical behavior and morphology. Polymer 2001, 42, 2491-2500. [CrossRef]

10. Kostrzewa, M.; Hausnerova, B.; Bakar, M.; Siwek, E. Effects of various polyurethanes on the mechanical and structural properties of an epoxy resin. J. Appl. Polym. Sci. 2011, 119, 2925-2932. [CrossRef] 
11. Bakar, M.; Kostrzewa, M.; Pawelec, Z. Preparation and properties of epoxy resin modified with polyurethane based on hexamethylene diisocyanate and different polyols. J. Therm. Comp. Mat. 2014, 27, 620-631. [CrossRef]

12. Bakar, M.; Duk, R.; Przybylek, M.; Kostrzewa, M. Mechanical and Thermal Properties of Epoxy Resin Modified with Polyurethane. J. Reinf. Plast. Compos. 2009, 28, 2107-2118. [CrossRef]

13. Tian, Q.; Rong, M.Z.; Zhang, M.Q.; Yuan, Y.C. Optimization of thermal remendability of epoxy via blending. Polymer 2010, 51, 1779-1785. [CrossRef]

14. Gaina, V.; Ursache, O.; Gaina, C.; Buruiana, E. Novel Thermally-Reversible Epoxy-Urethane Networks. Des. Monomers Polym. 2012, 15, 63-73. [CrossRef]

15. Ursache, O.; Gaina, C.; Gaina, V. Polyurethanes based on thermoreversible networks designed by Diels-Alder reaction. Exp. Polym. Lett. 2017, 6, 467-478. [CrossRef]

16. Gandini, A. The furan/maleimide Diels-Alder reaction: A versatile click-unclick tool in macromolecular synthesis. Prog. Polym. Sci. 2013, 38, 1-29. [CrossRef]

17. Liang, C.; Li, J.; Xia, M.; Li, G.; Luo, Y. Performance and Kinetics Study of Self-Repairing Hydroxyl-Terminated Polybutadiene Binders Based on the Diels-Alder Reaction. Polymers 2017, 9, 200. [CrossRef]

18. Fang, L.; Chen, J.; Zou, Y.; Xu, Z.; Lu, C. Thermally-Induced Self-Healing Behaviors and Properties of Four Epoxy Coatings with Different Network Architectures. Polymers 2017, 9, 333. [CrossRef]

19. Mallek, H.; Jegat, C.; Mignard, N.; Abid, M.; Abid, S.; Taha, M. Reversibly crosslinked self-healing PCL-based networks. J. Appl. Polym. Sci. 2013, 129, 954-964. [CrossRef]

20. Defize, T.; Riva, R.; Raquez, J.-M.; Dubois, P.; Jérôme, C.; Alexandre, M. Thermoreversibly Crosslinked Poly(E-caprolactone) as Recyclable Shape-Memory Polymer Network. Makromol. Rapid Commun. 2011, 32, 1264-1269. [CrossRef] [PubMed]

21. Raquez, J.-M.; Vanderstappen, S.; Meyer, F.; Verge, P.; Alexandre, M.; Thomassin, J.-M.; Jérôme, C.; Dubois, P. Design of Cross-Linked Semicrystalline Poly ( $\varepsilon$-caprolactone)-Based Networks with One-Way and Two-Way Shape-Memory Properties through Diels-Alder Reactions. Chem. Eur. J. 2011, 17, 10135-10143. [CrossRef] [PubMed]

22. Rivero, G.; Nguyen, L.-T.T.; Hillewaere, X.K.D.; Prez, F.E.D. One-Pot Thermo-Remendable Shape Memory Polyurethanes. Macromolecules 2014, 47, 2010-2018. [CrossRef]

23. Liu, X.; Du, P.; Liu, L.; Zheng, Z.; Wang, X.; Joncheray, T.; Zhang, Y. Kinetic study of Diels-Alder reaction involving in maleimide-furan compounds and linear polyurethane. Polym. Bull. 2013, 70, 2319-2335. [CrossRef]

24. Zhang, G.; Zhao, Q.; Yang, L.; Zou, W.; Xi, X.; Xie, T. Exploring Dynamic Equilibrium of Diels-Alder Reaction for Solid State Plasticity in Remoldable Shape Memory Polymer Network. ACS Macro Lett. 2016, 5, 805-808. [CrossRef]

25. Jiang, S.; Li, X.; An, L.; Jiang, B. Crystallization behavior of PCL in hybrid confined environment. Polymer 2001, 42, 3901-3907. [CrossRef]

26. Crescenzi, V.; Manzini, G.; Calzolari, B.; Borri, C. Thermodynamics of fusion of poly- $\beta$-propiolactone and poly- $\epsilon$-caprolactone. comparative analysis of the melting of aliphatic polylactone and polyester chains. Eur. Polym. J. 1972, 8, 449-463. [CrossRef]

27. Rueda-Larraz, L.; d'Arlas, B.F.; Tercjak, A.; Ribes, A.; Mondragon, I.; Eceiza, A. Synthesis and microstructure-mechanical property relationships of segmented polyurethanes based on a PCL-PTHF-PCL block copolymer as soft segment. Eur. Polym. J. 2009, 45, 2096-2109. [CrossRef]

28. Adachi, K.; Achimuthu, A.K.; Chujo, Y. Synthesis of Organic-Inorganic Polymer Hybrids Controlled by Diels-Alder Reaction. Macromolecules 2004, 37, 9793-9797. [CrossRef]

29. Gorna, K.; Polowinski, S.; Gogolewski, S. Synthesis and characterization of biodegradable poly(epsilon-caprolactone urethane)s. I. Effect of the polyol molecular weight, catalyst, and chain extender on the molecular and physical characteristics. J. Polym. Sci. Polym. Chem. 2002, 40, 156-170. [CrossRef]

30. Li, F.; Hou, J.; Zhu, W.; Zhang, X.; Xu, M.; Luo, X.; Ma, D.; Kim, B.K. Crystallinity and morphology of segmented polyurethanes with different soft-segment length. J. Appl. Polym. Sci. 1996, 62, 631-638. [CrossRef] 
31. Lakatos, C.; Czifrák, K.; Papp, R.; Karger-Kocsis, J.; Zsuga, M.; Kéki, S. Segmented linear shape memory polyurethanes with thermoreversible Diels-Alder coupling: Effects of polycaprolactone molecular weight and diisocyanate type. Exp. Polym. Lett. 2016, 10, 324-336. [CrossRef]

32. Kocsis, J.K.; Kéki, S. Review of Progress in Shape Memory Epoxies and Their Composites. Polymers 2018, 10, 34. [CrossRef]

33. Ratna, D.; Karger-Kocsis, J. Recent advances in shape memory polymers and composites: A review. J. Mater. Sci. 2008, 43, 254-269. [CrossRef]

34. Lakatos, C.; Czifrák, K.; Karger-Kocsis, J.; Daróczi, L.; Zsuga, M.; Kéki, S. Shape memory crosslinked polyurethanes containing thermoreversible Diels-Alder couplings. J. Appl. Polym. Sci. 2016, 133, 44145. [CrossRef]

(C) 2018 by the authors. Licensee MDPI, Basel, Switzerland. This article is an open access article distributed under the terms and conditions of the Creative Commons Attribution (CC BY) license (http:/ / creativecommons.org/licenses/by/4.0/). 